\title{
Three-Phase Active Harmonic Rectifier (AHR) to Improve Utility Input Current THD in Telecommunication Power Distribution System
}

\author{
Sangsun Kim, Member, IEEE, Maja Harfman Todorovic, Student Member, IEEE, and Prasad N. Enjeti, Fellow, IEEE
}

\begin{abstract}
Modern telecommunication power supply systems have several parallel-connected switch-mode rectifiers to provide -48 Vdc. A typical switch-mode rectifier configuration includes a three-phase diode rectifier followed by a dc-dc converter. Such a system draws significant harmonic currents for the utility, resulting in poor input power factor and high total harmonic distortion. In this paper, a three-phase active harmonic rectifier (AHR) scheme is proposed. In the AHR scheme, a diode rectifier module is replaced by a six-insulated-gate-bipolar-transistor pulsewidth-modulation rectifier to supply load harmonics as well as its own active power. Each dc-dc converter module is connected to a shared 48-V dc link. The AHR module together with parallel-connected switch-mode rectifiers is controlled to achieve clean input power characteristics. The VA ratings of the AHR scheme is compared with an active power filter approach. The control design is based on the synchronous reference frame approach. Analysis, simulation, and experimental results show that the AHR offers several advantages such as lower VA rating, better current control response, efficient use of the AHR dc link, small size, and stable dc-link voltage control.
\end{abstract}

Index Terms-Active harmonic rectifier (AHR), active power filter (APF), telecom rectifier, total harmonic distortion (THD).

\section{INTRODUCTION}

M ODERN telecommunication power systems require several three-phase rectifiers in parallel to obtain higher dc power with $-48 \mathrm{Vdc}$. Such a rectifier normally employs diodes or silicon-controlled rectifiers (SCR) to interface with the electric utility due to economic reasons. The rectifier-type utility interface causes significant harmonic currents, resulting in poor input power factor and high total harmonic distortion (THD), which contributes to an inefficient use of electric energy. The above-mentioned rectifier is referred to as a nonlinear load. The

Paper IPCSD 03-069, presented at the 2003 IEEE Applied Power Electronics Conference and Exposition, Miami Beach, FL, February 9-13, and approved for publication in the IEEE TRANSACTIONS ON INDUSTRY APPLICATIONS by the Industrial Power Converter Committee of the IEEE Industry Applications Society. Manuscript submitted for review December 1, 2002 and released for publication May 16, 2003.

S. Kim was with the Power Electronics and Power Quality Laboratory, Department of Electrical Engineering, Texas A\&M University, College Station, TX 77843-3128 USA. He is now with the Power Conversion Division, Lite-On, Inc., Houston, TX 77070 USA (e-mail: sskim@ ieee.org).

M. Harfman Todorovic and P. N. Enjeti are with the Power Electronics and Power Quality Laboratory, Department of Electrical Engineering, Texas A\&M University, College Station, TX 77843-3128 USA (e-mail: p.enjeti@ieee.org). Digital Object Identifier 10.1109/TIA.2003.816530 proliferation of rectifier loads deteriorates the quality of voltage and current waveforms. Further, harmonic currents can lead to equipment overheating, malfunction of solid-state equipment, and interference with communication systems [1]-[3]. IEEE 519 and IEC EN 61000-3 standards specify regulations governing harmonic compliance [4], [5]. The passive filter has been a viable approach because of low cost and high efficiency [6], [7]. However, the performance of the passive scheme has a limitation since the addition of the passive filter interfaces with the system impedance and causes resonance with other networks. Numerous active solutions which are becoming a more effective means to meet the harmonic standards by overcoming the drawback of the passive filter have been proposed [8]-[11].

Active power filters (APFs) employing a pulsewidth-modulation (PWM) voltage-source inverter seem to be the most preferred scheme for canceling load harmonics. However, the general voltage-source inverter topology employs a relatively large dc-link capacitor to serve as a constant dc voltage source. Therefore, this scheme suffers from a bulky electrolytic capacitor, higher switching losses, and its associated dc-link voltage control issues due to reduced damping.

In this paper, a three-phase active harmonic rectifier (AHR) scheme based on space-vector PWM (SVPWM) is proposed. The AHR module together with parallel-connected switch-mode rectifiers [Fig. 2(a)] is controlled to achieve clean input power characteristics. The AHR is compared with the APF based on the analysis of VA power rating. The control system is designed on the synchronous $d q$ reference frame where a low-pass filter to cancel harmonics offers better performance than the stationary reference frame. The converter fulfills harmonic cancellation as well as powering active power to its own load by PWM rectification [12], [13]. Therefore, the converter carries a fundamental current for active power and harmonics for the nonlinear loads. The proposed scheme provides the following advantages:

- reduced dc-link capacitor banks;

- VA rating of the AHR is lower than that of the APF with rectifier current THD greater than 35\%;

- harmonic rms current of the AHR is $(N-1) / N$ times smaller than that of APF, where $N$ is the number of dc-dc converter modules.

- better current control response;

- stable control system due to damping provided by the load; 


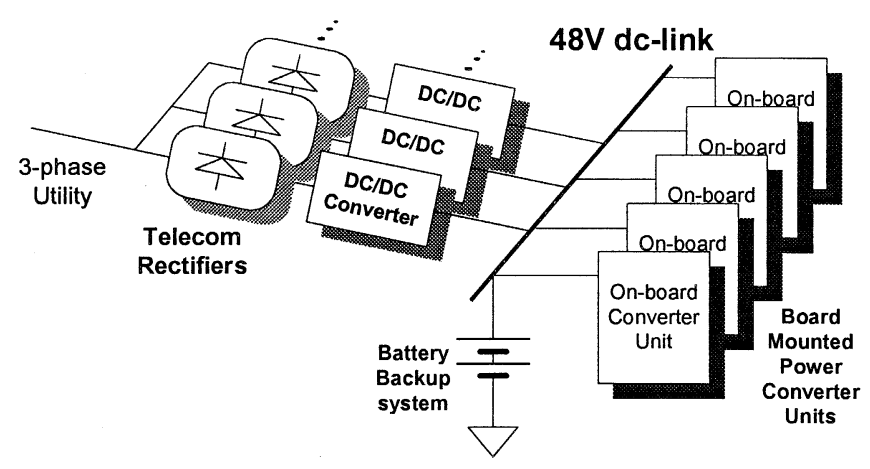

(a)

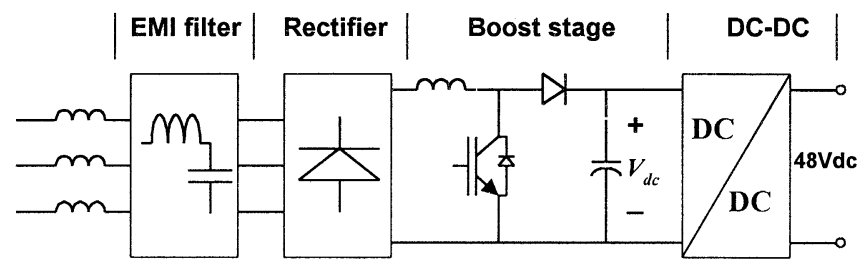

(b)

Fig. 1. Telecom rectifier power system. (a) Telecom distributed rectifiers. (b) Basic telecom rectifier topology.

- no additional boost stage;

- efficient use of PWM rectifier.

\section{TELECOM POWER SYSTEM}

Modern telecommunication systems require a higher dc power. An example system requirement consists of $-48 \mathrm{Vdc}$ and $800 \mathrm{~A}(38.4 \mathrm{~kW})$ [14]. All of the equipment runs on $\mathrm{dc}$ voltage generated by ac-fed redundant rectifiers of which the purpose is to supply power to the equipment. Fig. 1(a) shows a distributed rectifier system where a three-phase utility power is transferred into $48 \mathrm{Vdc} .^{1}$ The telecom rectifiers consist of a rectifier stage, a dc-to-dc converter, and a battery backup system. The major portion of the load is the logic circuitry in board-mounted power (BMP) converter units used to convert $48 \mathrm{~V}$ to $5 \mathrm{~V}$ and $\pm 12 \mathrm{~V}$. The purpose of the dc-dc converter is to transfer high dc-link voltage to lower voltage $48 \mathrm{~V}$ and provide isolation. Each paralleled dc-dc converter module requires a current-sharing mechanism to ensure even current distribution. A battery backup system on the $48-\mathrm{V}$ dc bus is required to support the critical loads in case of utility failure. The basic topology of the telecom rectifier is shown in Fig. 1(b). The boost stage is used only to regulate dc-link voltage for a wide input voltage range. Since the power supply employs diode rectifiers because of economic reasons, the high-power rectifiers result in more serious problems related to harmonic currents. Such a typical rectifier may have more than $30 \%$ THD of input current. Fig. 2 shows an example of a telecommunication power system. An AHR [Fig. 2(a)] or APF [Fig. 2(b)] is embedded in a rectifier slot and is rack mountable so that the THD in the utility current can be improved by eliminating harmonic contents. The AHR with harmonic filtering function supplies

${ }^{1}$ GALAXY Switchmode Rectifier 595 Series, Tyco Electronics, Harrisburg, PA, 2001.

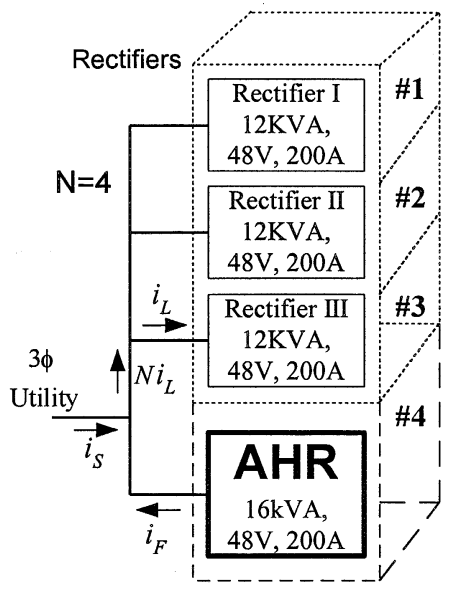

(a)

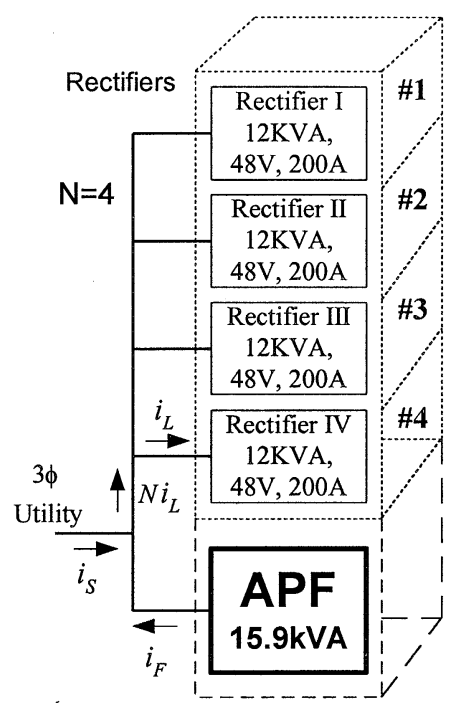

(b)

Fig. 2. Example telecom power system as a plug-in rack-mountable module. (a) Rectifier system with AHR $\left(P_{o}=38.4 \mathrm{~kW}\right)$. (b) Rectifier system with APF $\left(P_{o}=38.4 \mathrm{~kW}\right)$

active power and harmonic currents while the APF generates load harmonics and optional reactive power.

\section{PROPOSED AHR SCHEME}

Fig. 3 shows the basic harmonic cancellation techniques using AHR [Fig. 3(a)] and APF [Fig. 3(b)]. The proposed AHR scheme consists of rectifier nonlinear loads, three-leg PWM rectifier, paralleled dc-dc converters, and battery backup system. Since rectifier load produces harmonic currents such as the 5th, 7th, etc., a PWM rectifier with active harmonic filtering capability, called the AHR, compensates for load harmonics as well as supplying active power to its own load. The AHR carries a fundamental current for active power and harmonics for the nonlinear loads to make the input current sinusoidal. Fig. 4 shows the current waveforms for the rectifier input, AHR, and utility currents. The reactive power of the load also can be optionally compensated to improve power factor. 


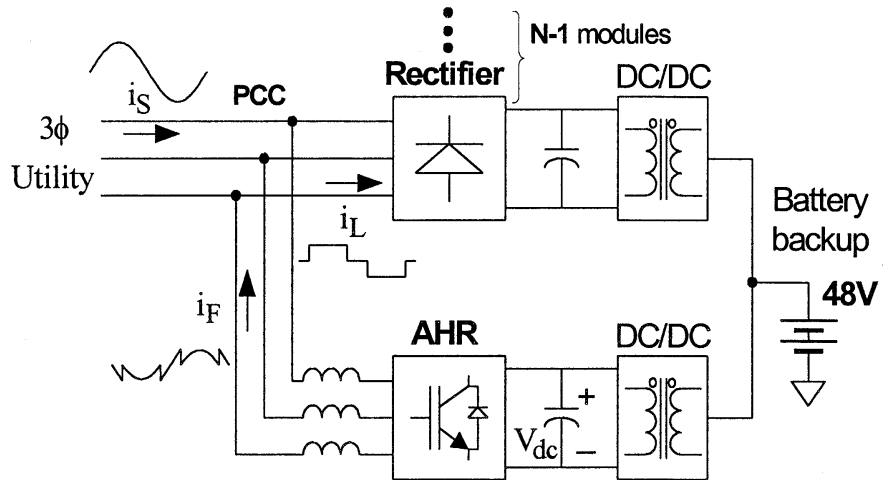

(a)

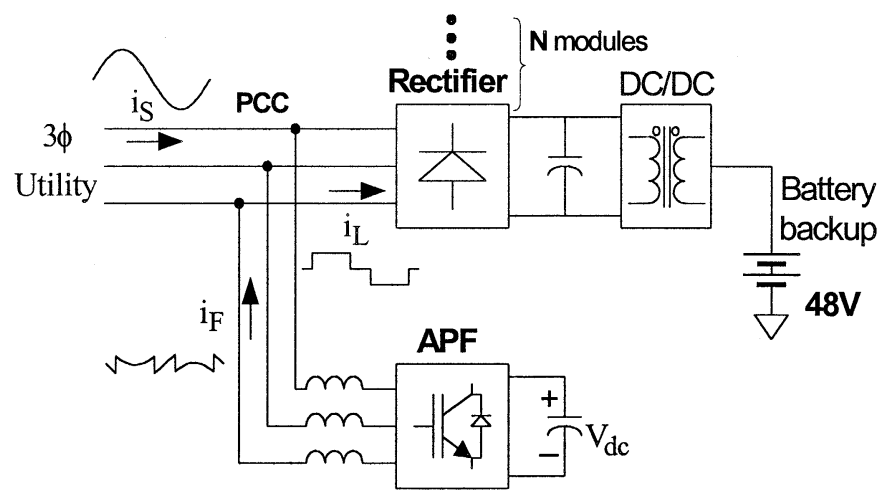

(b)

Fig. 3. Active harmonic filtering techniques in telecom distributed system. (a) AHR. (b) APF.

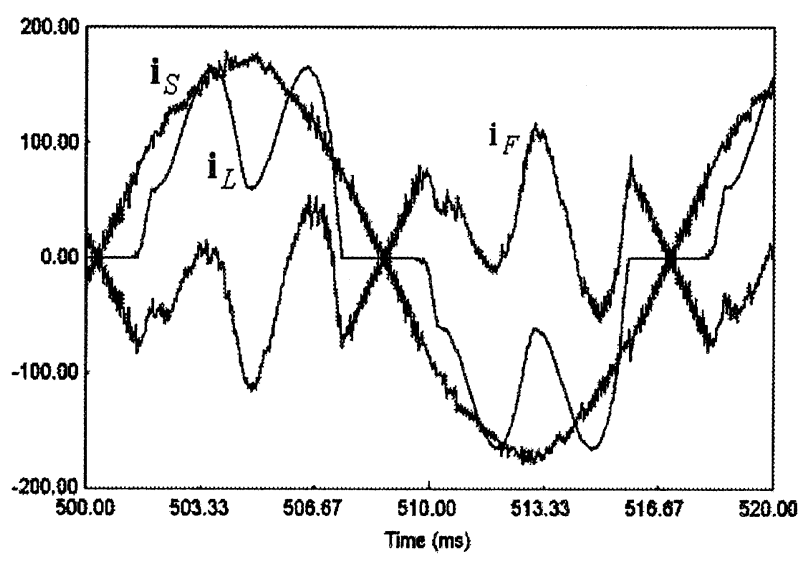

Fig. 4. Current waveforms for the proposed AHR scheme.

To control the active harmonic rectifier, bidirectional power flows are required for 5 th and 7 th harmonic currents. The input source current is defined as

$$
\mathbf{i}_{S}=N \mathbf{i}_{L}-\mathbf{i}_{F}
$$

where $i_{S}, N i_{L}$, and $i_{F}$ denote utility, load, and APF currents, respectively. Fig. 5 shows the fundamental $60-\mathrm{Hz}$ current and voltage vectors for the AHR with and without reactive power

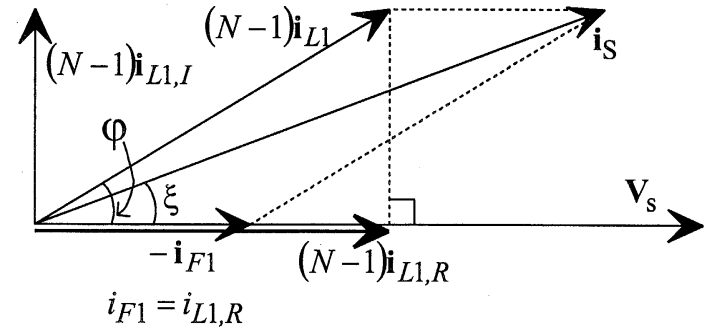

(a)

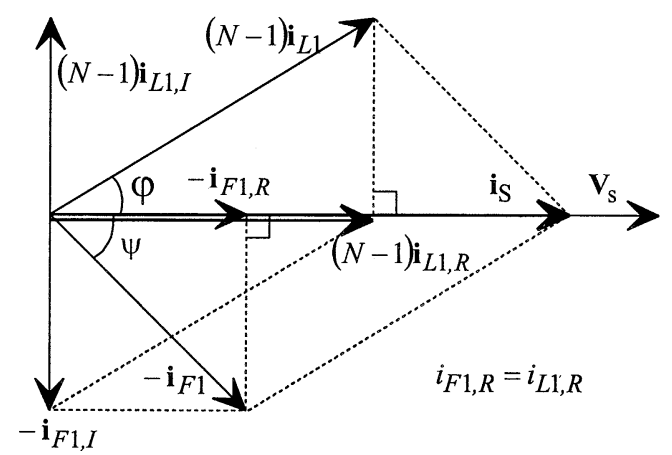

(b)

Fig. 5. Fundamental $60-\mathrm{Hz}$ current vector diagrams. (a) Without reactive power compensation. (b) With reactive power compensation.

compensation. Assuming no reactive power compensation [Fig. 5(a)], the steady-state utility current can be obtained by

$$
\begin{aligned}
i_{s} & =\sqrt{(N-1)^{2} i_{L 1, I}^{2}+\left(i_{F 1}+(N-1) i_{L 1, R}\right)^{2}} \\
& =i_{L 1} \sqrt{(1-2 N) \sin ^{2} \varphi+N^{2}}
\end{aligned}
$$

where $N$ is the number of dc-dc modules and $i_{L 1}$ denotes the fundamental load current of each rectifier module. $R$ and $I$ denote real and imaginary parts, respectively. $i_{F 1}=i_{L 1} \cos \varphi$ since $i_{F 1}$ is synchronized with the utility voltage.

Displacement power factor angle $\xi$ after compensation is

$$
\xi=\tan ^{-1}\left(\frac{N-1}{N} \tan \varphi\right)<\varphi .
$$

The input displacement power factor is derived without reactive power compensation

$$
\cos \xi=\frac{N \cos \varphi}{\sqrt{(1-2 N) \sin ^{2} \varphi+N^{2}}} .
$$

On the other hand, the fundamental utility current depends on the displacement power angle $\varphi$ with reactive power compensation. Input current is similarly calculated as

$$
i_{S}=i_{F 1, R}+(N-1) i_{L 1, R}=N \cdot i_{L 1} \cdot \cos \varphi
$$

where $i_{F 1, R}=i_{L 1} \cos \varphi$ and $i_{F 1, I}=i_{L 1} \sin \varphi$. The angle between the input voltage and the AHR current is

$$
\begin{aligned}
& \psi=\tan ^{-1}\left(\frac{i_{F 1, I}}{i_{F 1, R}}\right)=\tan ^{-1}(\tan \varphi) \\
& \psi=\varphi .
\end{aligned}
$$

The rms harmonic currents of the AHR and APF are relatively given as

$$
\begin{aligned}
& i_{F, h a r}=(N-1) \cdot i_{L, h a r} \\
& i_{F, h a r}=N \cdot i_{L, h a r} .
\end{aligned}
$$




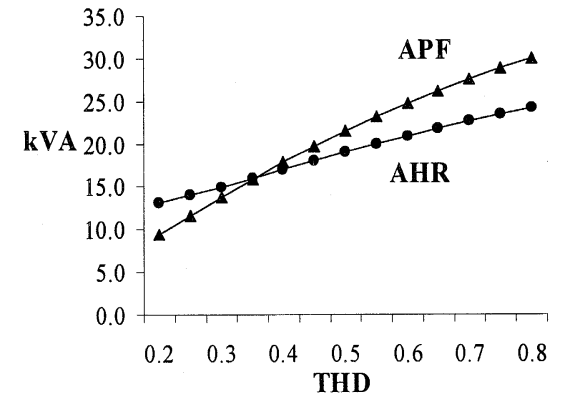

(a)

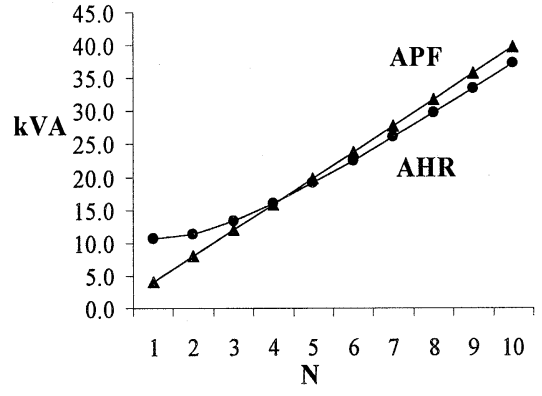

(b)

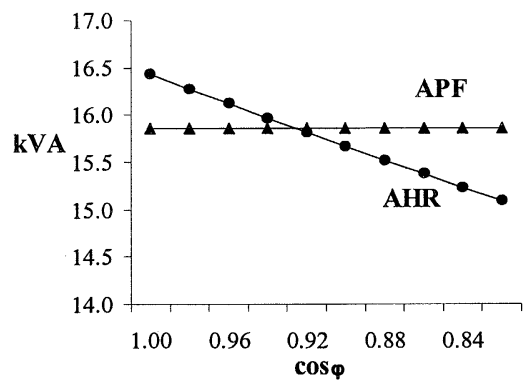

(c)

Fig. 6. VA ratings without reactive power compensation ( $\left.P_{\text {in }}=48 \mathrm{kVA}, P_{o}=38.4 \mathrm{~kW}\right)$. (a) THD: variable. (b) $\mathrm{N}$ : variable. (c) $\cos \varphi$ : variable.

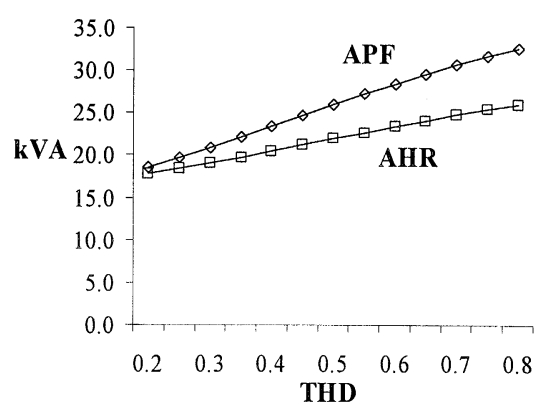

(a)

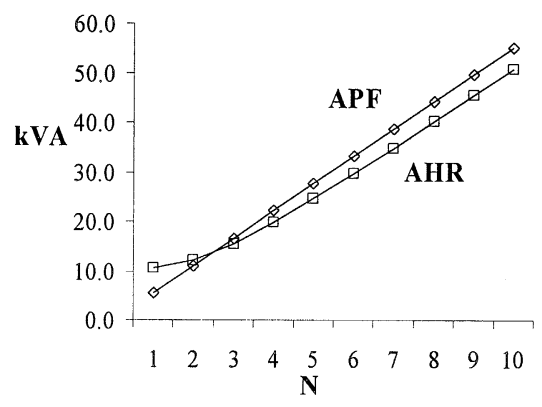

(b)

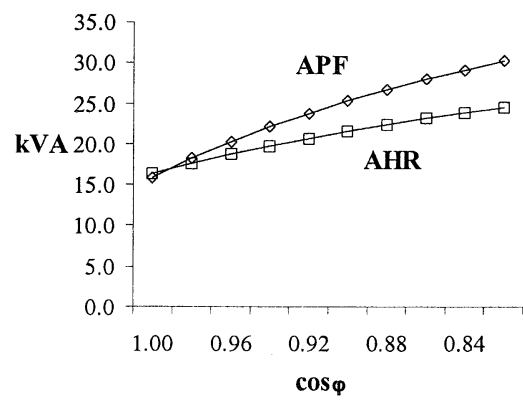

(c)

Fig. 7. VA ratings of AHR and APF with reactive power compensation ( $\left.P_{\text {in }}=48 \mathrm{kVA}, P_{o}=38.4 \mathrm{~kW}\right)$. (a) THD: variable. (b) N: variable. (c) $\cos \varphi$ : variable.

The harmonic current of the AHR is $(N-1) / N$ times the APF harmonic currents. The VA ratings of the proposed AHR with and without reactive power compensation are, respectively,where the subscript NL denotes a nonlinear load. In the case

$$
\begin{aligned}
V A_{\mathrm{AHR}}= & \sqrt{\frac{(N-1)^{2}\left(\sin ^{2} \varphi+T H D_{\mathrm{NL}}^{2}\right)+\cos ^{2} \varphi}{1+T H D_{\mathrm{NL}}^{2}}} \\
& \cdot V A_{\mathrm{NL}}, \quad \text { (with) } \\
V A_{\mathrm{AHR}}= & \sqrt{\frac{\cos ^{2} \varphi+(N-1)^{2} T H D_{\mathrm{NL}}^{2}}{1+T H D_{\mathrm{NL}}^{2}}} \\
& \cdot V A_{\mathrm{NL}}, \quad \text { (without) }
\end{aligned}
$$

of the APF, the VA rating is given by

$$
V A_{\mathrm{APF}}=\sqrt{\frac{T H D_{\mathrm{NL}}^{2}+\sin ^{2} \varphi}{1+T H D_{\mathrm{NL}}^{2}}} \cdot N \cdot V A_{\mathrm{NL}} .
$$

If the reactive power is not compensated, $\varphi=0$. Fig. 6 shows the VA rating comparison between the APF and AHR without reactive power compensation assuming THD $=35 \%, N=4$, and $\cos \varphi=0.94$. The VA rating of the AHR is smaller than that of the APF if THD is greater than $35 \%, N$ is greater than 4 , and displacement power factor is less than 0.92. Similarly, the VA rating of the AHR is shown in Fig. 7 when reactive power is compensated.

\section{CONTROL SySTEM}

To control the proposed AHR, a harmonic reference current generator is required. Fig. 8 shows several techniques to generate harmonic reference currents on the synchronous reference

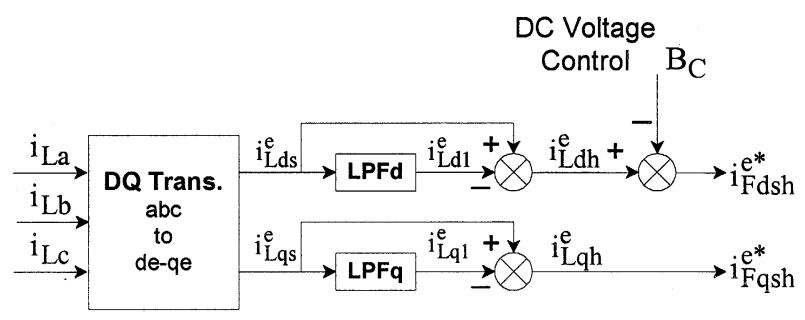

(a)

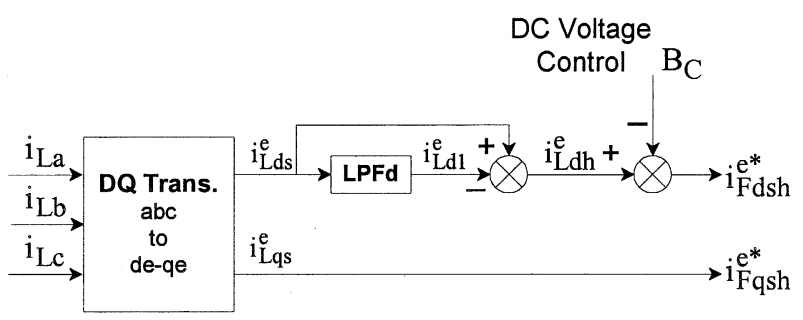

(b)

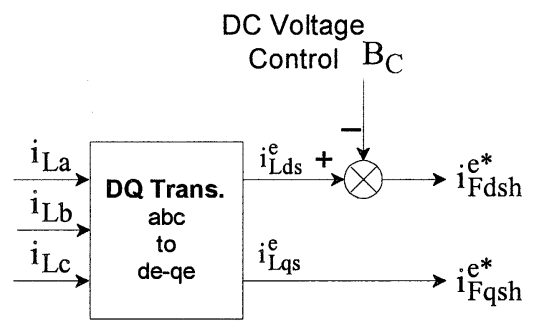

(c)

Fig. 8. Harmonic reference current generators. (a) Without reactive power compensation. (b) With reactive power compensation. (c) Simple block diagram for reactive power compensation.

frame (SRF). A low-pass filter can eliminate all harmonic currents except dc component since the harmonic frequency is far 
TABLE I

$d q$ TRANSFORMATION FOR SEVERAL COMPONENTS

\begin{tabular}{|c|c|}
\hline Input $\left(\mathrm{i}_{\text {Labcs }}\right)$ & Output ( $\mathrm{i}_{\text {Ldqns }}$ ) \\
\hline $\begin{array}{l}\text { Fundamental with power angle } \\
\qquad I_{1}\left[\begin{array}{c}\sin (\omega t-\varphi) \\
\sin (\omega t-\varphi-2 \pi / 3) \\
\sin (\omega t-\varphi+2 \pi / 3)\end{array}\right]\end{array}$ & $I_{1}\left[\begin{array}{c}\cos \varphi \\
-\sin \varphi \\
0\end{array}\right]$ \\
\hline $\begin{array}{c}\text { Negative Sequence } \\
I_{6 h-1}\left[\begin{array}{c}\sin \{(6 h-1) \omega t\} \\
\sin \{(6 h-1)(\omega t-2 \pi / 3)\} \\
\sin \{(6 h-1)(\omega t+2 \pi / 3)\}\end{array}\right]\end{array}$ & $I_{6 h-1}\left[\begin{array}{c}-\cos (6 h \omega t) \\
\sin (6 h \omega t) \\
0\end{array}\right]$ \\
\hline $\begin{array}{c}\text { Positive Sequence } \\
I_{6 h+1}\left[\begin{array}{c}\sin \{(6 h+1) \omega t\} \\
\sin \{(6 h+1)(\omega t-2 \pi / 3)\} \\
\sin \{(6 h+1)(\omega t+2 \pi / 3)\}\end{array}\right]\end{array}$ & $I_{6 h+1}\left[\begin{array}{c}\cos (6 h \omega t) \\
\sin (6 h \omega t) \\
0\end{array}\right]$ \\
\hline $\begin{array}{c}\text { Zero Sequence } \\
I_{6 h-3}\left[\begin{array}{c}\sin (6 h-3) \omega t \\
\sin (6 h-3) \omega t \\
\sin (6 h-3) \omega t\end{array}\right]\end{array}$ & $\frac{I_{6 h-3}}{\sqrt{2}}\left[\begin{array}{c}0 \\
0 \\
\sin (6 h-3) \omega t\end{array}\right]$ \\
\hline
\end{tabular}

$* \mathrm{~h}=1,2,3 \ldots$

enough from the dc component on the frequency domain. That is the reason why the low-pass filter provides better performance on the SRF.

\section{A. Without Reactive Power Compensation}

In steady state, the harmonic reference currents contain only load harmonic components such as the 5th, 7th, etc., assuming that reactive power is not compensated [Fig. 8(a)]. Reactive power is optionally compensated since the power rating of active power filter is increased by adding fundamental current for reactive power compensation. $d q$ transformation results are tabulated in Table I for fundamental current, negative/positive sequences of harmonics, and zero sequence. Three-phase balanced currents are transferred into a $d$ component with a certain dc quantity and a $q$ component with zero. Negative-sequence harmonic (6h-1) components include 5th, 11th, 17th, etc., while the positive-sequence harmonics $(6 h+1)$ are 7 th, 13th, 19th, etc. $d q$ transformations of negative and positive sequences result in $6 \mathrm{~h}$ harmonics (6th, 12th, etc.). Zero sequences (6h-3) such as the $3 \mathrm{rd}$, 9th, 15th, etc., are transformed into their own components. It is noted that 5 th and 7 th harmonics cause a 6 th harmonic component while 11th and 13th harmonics generate 12th harmonic current on the SRF. Therefore, even harmonics of the SRF are affected on the harmonic reference currents. Harmonic reference currents can be obtained by using low-pass filters (LPFd, LPFq) which eliminate the even harmonics except dc component. The cutoff frequency of the low-pass filter is set to from 1 to $50 \mathrm{~Hz}$. Higher cutoff frequency allows fast control response, but results in distorted utility currents. On the SRF, dc quantity, $i_{L d q 1}^{e}$, represents the fundamental current of the phase current.
Final expected utility current can be estimated via an inverse $d q$ transformation after compensating for the harmonics

$$
\mathbf{i}_{a b c s}=\mathbf{T}^{-1}(\theta)\left[\begin{array}{c}
i_{L d 1}^{e} \\
i_{L q 1}^{e} \\
0
\end{array}\right]=\mathbf{i}_{L 1}
$$

where transformation matrix is given as

$$
\mathbf{T}(\theta)=\frac{2}{3}\left[\begin{array}{ccc}
\sin \theta & \sin \left(\theta-\frac{2}{3} \pi\right) & \sin \left(\theta+\frac{2}{3} \pi\right) \\
\cos \theta & \cos \left(\theta-\frac{2}{3} \pi\right) & \cos \left(\theta+\frac{2}{3} \pi\right) \\
\frac{1}{\sqrt{2}} & \frac{1}{\sqrt{2}} & \frac{1}{\sqrt{2}}
\end{array}\right] .
$$

The input current vector is the same as that of the load fundamental current $\mathbf{i}_{L 1}$. Harmonic reference currents $i_{F d q s h}^{*}$ are obtained from the even harmonics as

$$
\begin{gathered}
\mathbf{i}_{F d q s h}^{e^{*}}=\left[\begin{array}{c}
i_{F d s h}^{*} \\
i_{F q s h}^{*}
\end{array}\right]=\left[\begin{array}{c}
i_{L d h}^{e}-B_{c} \\
i_{L q h}^{e}
\end{array}\right] \\
\mathbf{i}_{L d q h}^{e}=\left[\begin{array}{c}
i_{L d h}^{e} \\
i_{L q h}^{e}
\end{array}\right]=\left[\begin{array}{c}
i_{L d s}^{e}-i_{L d 1}^{e} \\
i_{L q s}^{e}-i_{L q 1}^{e}
\end{array}\right]
\end{gathered}
$$

where $\mathbf{i}_{L d q h}^{e}$ denotes the even harmonics and $B_{c}$ is obtained from dc-bus voltage control. The AHR current due to the dc-link voltage control is expressed as

$$
\mathbf{i}_{\text {Fabcs }}=-\mathbf{T}^{-1}(\theta)\left[\begin{array}{c}
B_{c} \\
0 \\
0
\end{array}\right] .
$$

Thus, dc-bus voltage control factors can be simply added into the reference currents since dc-bus voltage depends on the fundamental AHR current, the magnitude of which is controllable. Fig. 9 shows the current waveforms on the SRF based upon the load currents. The harmonic reference currents $i_{F d q s h}$ contain $6 \mathrm{~h}$ harmonics mainly having 6 th harmonic component.

\section{B. With Reactive Power Compensation}

On the other hand, the power factor angle between utility voltage and rectifier load current is calculated from Fig. 10

$$
\varphi=\tan ^{-1}\left(\frac{i_{L q 1}^{e}}{i_{L d 1}^{e}}\right) .
$$

To compensate for the reactive power as well as the load harmonics, the expected utility current is

$$
\begin{aligned}
\mathbf{i}_{a b c s} & =\mathbf{T}^{-1}(\theta)\left[\begin{array}{c}
i_{L d 1}^{e} \\
0 \\
0
\end{array}\right] \\
i_{L d 1}^{e} & =i_{L 1} \cos \varphi .
\end{aligned}
$$

$\mathbf{i}_{L q 1}^{e}$ must become a fundamental AHR current. $\mathbf{i}_{S}$ is synchronized with the utility voltage so that the unity power factor can be achieved. Therefore, $i_{L q s}^{e}$ becomes $q$-axis AHR reference current $i_{F q s h}^{e^{*}}$ which has dc and even harmonics

$$
i_{F q s h}^{*}=i_{L q s}^{e}
$$

while $d$ component $i_{F d s h}^{e^{*}}$ is calculated from (14). The dc component $i_{L q 1}^{e}$ in $i_{L q s}^{e}$ represents phase angle $\varphi$. Fig. 8(b) shows the block diagram of harmonic reference current generator to compensate for reactive power as well as load harmonics. The 


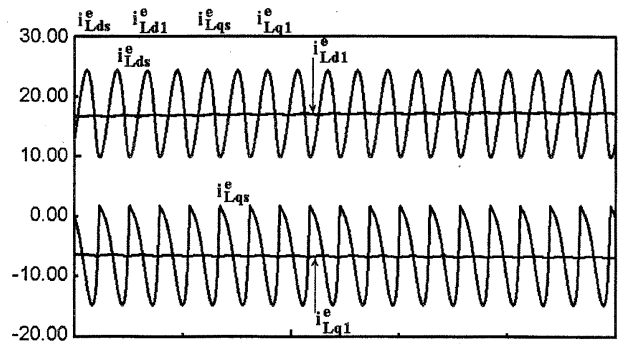

(a)

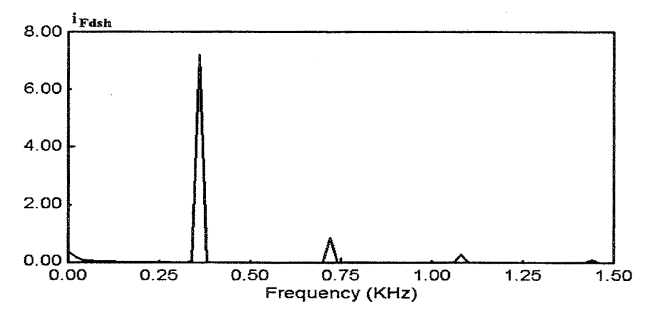

(b)

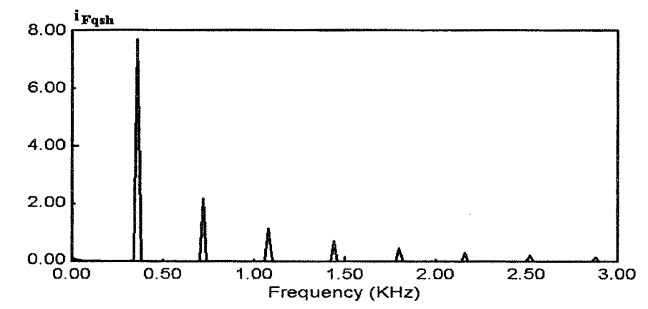

(c)

Fig. 9. Current waveforms on synchronous reference frame. (a) $d q$-axes currents. (b) Spectrum of $i_{F d s h}$. (c) Spectrum of $i_{F q s h}$.

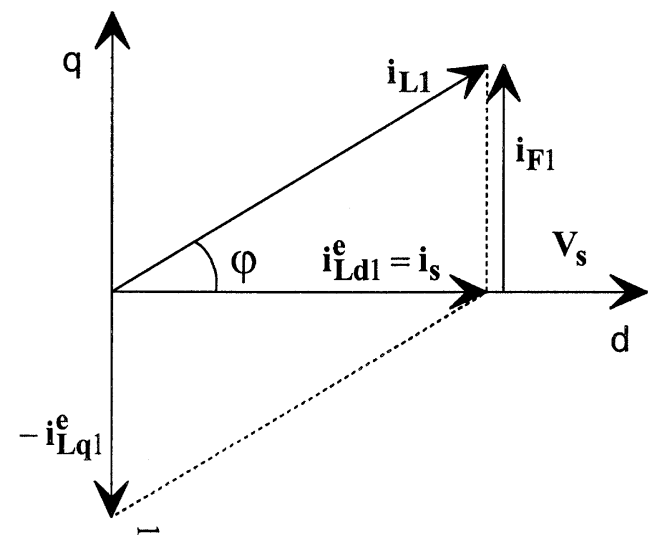

Fig. 10. Current vectors with power angle $\varphi$.

final fundamental current of the AHR is generated from the dc quantity $i_{L q 1}^{e}$

$$
\begin{aligned}
\mathbf{i}_{\text {Fabcs }} & =\mathbf{T}^{-1}(\theta)\left[\begin{array}{c}
0 \\
i_{L q 1}^{e} \\
0
\end{array}\right] \\
& =\sin \varphi \cdot I_{L 1}\left[\begin{array}{c}
\cos \theta \\
\cos \left(\theta-\frac{2}{3} \pi\right) \\
\cos \left(\theta+\frac{2}{3} \pi\right)
\end{array}\right]
\end{aligned}
$$

where $i_{L q 1}^{e}=\sin \varphi \cdot i_{L 1}$, and the current flowing out of the AHR has a leading angle $\pi / 2$. Fig. 11 shows the current waveforms

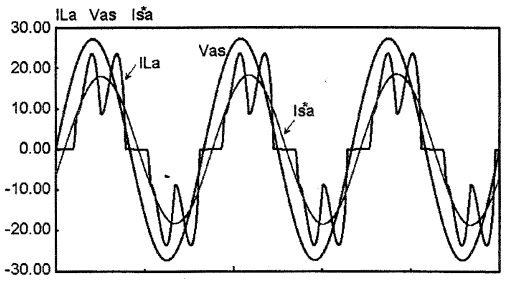

(a)

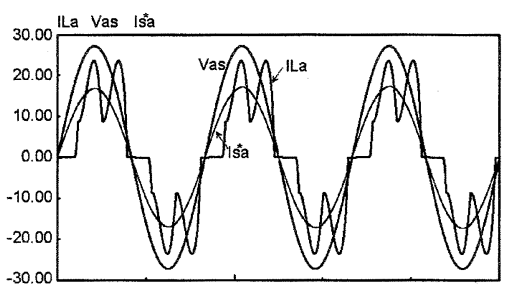

(b)

Fig. 11. Current waveforms in terms of reactive power compensation. (a) Without reactive power compensation. (b) With reactive power compensation.

in terms of reactive power compensation on the stationary reference frame. It is clear that the expected utility current with reactive power compensation is synchronized with the utility voltage. The AHR current $I_{F a}^{*}$ is calculated by an inverse $d q$ transformation of harmonic reference current $i_{F d q s h}^{*}$. Two APF currents are differentiated from the fundamental component. The simplified block diagram including reactive power is shown in Fig. 8(c).

\section{Design ExAmple}

An AHR design is based on the telecommunication rectifier system shown in Fig. 2(a). The total rectifier VA rating $\left(V A_{\mathrm{NL}}\right)$ is $48 \mathrm{kVA}$, total output power $38.4 \mathrm{~kW}$, THD $35 \%$, efficiency $90 \%, N=4$, and $\cos \varphi=0.94$. The AHR design specifications are as follows:

input voltage: $208 \mathrm{~V}$;

input current: $38 \mathrm{~A}$;

dc bus voltage: $380 \mathrm{~V}$;

rectifier current THD: $35 \%$;

input inductor: $1[\mathrm{mH}]=0.12[\mathrm{pu}]$;

output capacitor: $5.8[\mathrm{mF}]=6.7[\mathrm{pu}]$;

switching frequency: $16.4 \mathrm{kHz}$.

The VA rating of the AHR from (9) and (10) is

$$
\begin{aligned}
V A_{\mathrm{AHR}} & =16 \mathrm{kVA} \quad \text { (without) } \\
& =19.7 \mathrm{kVA} \quad \text { (with). }
\end{aligned}
$$

The VA rating of the APF from (11) is

$$
\begin{aligned}
V A_{\mathrm{APF}} & =15.9 \mathrm{kVA} & & \text { (without) } \\
& =22.1 \mathrm{kVA} & & \text { (with). }
\end{aligned}
$$

\section{EXPERIMENTAL RESULTS}

The proposed three-phase active harmonic rectifier system is implemented on a fixed-point digital signal processor (DSP), TMS320LF2407. A proportional-integral (PI) current controller regulates harmonic current on the synchronous 


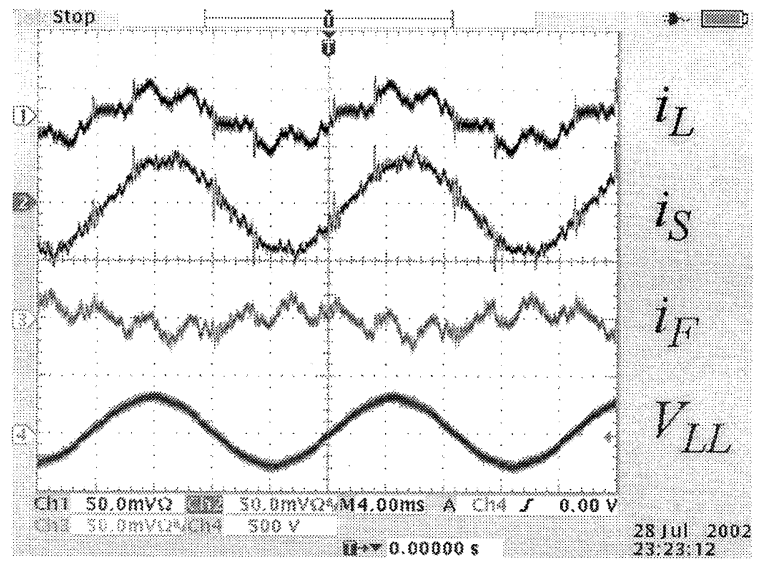

(a)

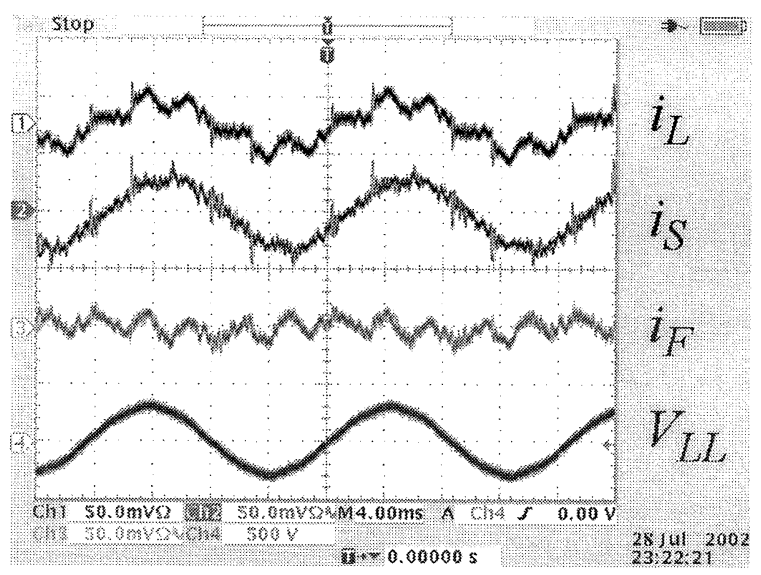

(b)

Fig. 12. Experimental results. (a) AHR. (b) APF

reference frame and SVPWM technique is employed for the voltage-source inverter. Fig. 12(a) shows the control performance of the proposed scheme from experimental results without reactive power compensation. The AHR compensates for load harmonics and supplies active power. The APF results are shown in Fig. 12(b). The AHR current contains a fundamental component and load harmonics while the APF generates only load harmonic currents.

\section{CONCLUSION}

In this paper, a three-phase AHR scheme has been presented for a telecommunication power distribution system. The AHR is able to compensate for rectifier harmonics as well as supply active power. Harmonic reference current generators were shown. From the VA rating analysis of the AHR and APF, it is shown that the AHR scheme in a telecom power system provides less VA power ratingand includes several advantages such as better current control response, efficient use of the AHR dc link, small size, and stable dc-link voltage control. The experimental results verify the performance of the proposed AHR system.

\section{REFERENCES}

[1] J.-S. Lai and T. S. Key, "Effectiveness of harmonic mitigation equipment for commercial office buildings," IEEE Trans. Ind. Applicat., vol. 33, pp. 1104-1110, July/Aug. 1997.

[2] S. L. Clark, P. Famouri, and W. L. Cooley, "Elimination of supply harmonics: an evolution of current compensation and active filtering methods," in Conf. Rec. IEEE-IAS Annu. Meeting, 1994, pp. 1699-1704.

[3] H. O. Aintablian and H. W. Hill Jr., "Harmonic currents generated by personal computers and their effects on the distribution system neutral current," in Conf. Rec. IEEE-IAS Annu. Meeting, 1993, pp. 1483-1489.

[4] IEEE Recommended Practices and Requirements for Harmonic Control in Electrical Power Systems, IEEE Std. 519-1992, Apr. 1993.

[5] Electromagnetic Compatibility (EMC)-Part 3: Limits-Section 2: Limits for Harmonic Current Emissions (equipment input current $<=$ 16 A per phase), IEC 1000-3-2, 1st ed., 1995.

[6] G. T. Heydt, Electric Power Quality, 2nd ed. West Lafayette, IN: Stars in a Circle, 1991.

[7] H. Akagi, "New trends in active filters for power conditioning," IEEE Trans. Ind. Applicat., vol. 32, pp. 1312-1322, Nov./Dec. 1996.

[8] F. Z. Peng, H. Akagi, and A. Nabae, "A novel harmonic power filter," in Proc. IEEE PESC'88, vol. 2, 1988, pp. 1151-1159.

[9] V. B. Bhavaraju and P. N. Enjeti, "Analysis and design of an active power filter for balancing unbalanced loads," IEEE Trans. Power Electron., vol. 8, pp. 640-647, Oct. 1993.

[10] Y. Sato, T. Sugita, and T. Kataoka, "A new control method for current source active power filters," in Conf. Rec. IEEE-IAS Annu. Meeting, 1997, pp. 1463-1470.

[11] A. van Zyl, J. H. R. Enslin, and R. Spee, "Converter based solution to power quality problems on radial distribution lines," in Conf. Rec. IEEE-IAS Annu. Meeting, 1995, pp. 2573-2580.

[12] A. D. Le Roux, J. A. Du Toit, and J. H. R. Enslin, "Integrated active rectifier and power quality compensator with reduced current measurement," IEEE Trans. Ind. Electron., vol. 46, pp. 504-511, June 1999.

[13] F. Abrahamsen and A. David, "Adjustable speed drive with active filtering capability for harmonic current compensation," in Conf. Rec. IEEE-IAS Annu. Meeting, 1995, pp. 1137-1143.

[14] R. Redl and A. S. Kislovski, "Telecom power supplies and power quality," in Proc. INTELEC'95, 1995, pp. 13-21.

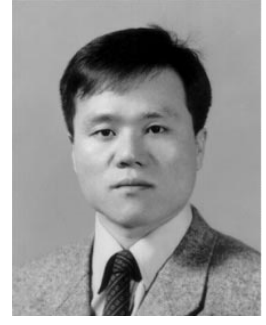

Sangsun Kim (S'00-M'02) was born in Cheon-nam, Korea, in 1969. He received the B.S. and M.S. degrees from Chung-Ang University, Seoul, Korea, in 1995 and 1997, respectively, and the Ph.D. degree from Texas A\&M University, College Station, in 2002, all in electrical engineering.

Since August 2002, he has been a Senior R\&D Engineer with Lite-On Electronics, Houston, TX. His research interests include applications of active harmonic filters, DSP-based power-factor correction, and adjustable-speed drives.

Dr. Kim was a member of the team that received a Grand Prize Award in the 2001 Future Energy Challenge sponsored by the U.S. Department of Energy.

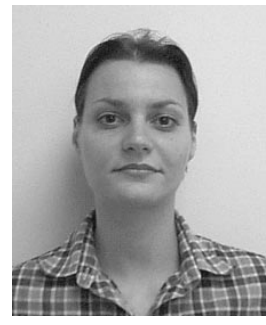

Maja Harfman Todorovic (S'02) was born in Belgrade, Serbia and Montenegro. She received the B.S. degree in electrical engineering from the School of Electrical Engineering, University of Belgrade, Belgrade, Serbia and Montenegro, in 2001. She is currently working toward the M.S. degree in the Department of Electrical Engineering, Texas A\&M University, College Station.

Her research interests include power electronics and digital signal processing, with an emphasis on three-phase inverters. 


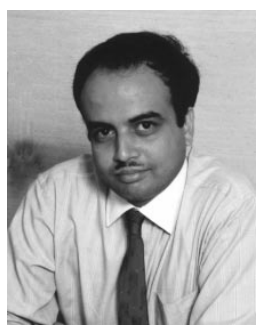

Prasad N. Enjeti (M'85-SM'88-F'00) received the B.E. degree from Osmania University, Hyderabad, India, the M.Tech degree from Indian Institute of Technology, Kanpur, India, and the Ph.D. degree from Concordia University, Montreal, QC, Canada, in 1980, 1982, and 1988, all in electrical engineering. In 1988, he joined the Department of Electrical Engineering, Texas A\&M University, College Station, as an Assistant Professor. In 1994, he was promoted to Associate Professor and, in 1998, he became a full Professor. His primary research interests are advance converters for power supplies and motor drives, power quality issues and active power filter development, converters for fuel cells, microturbine wind energy systems, power electronic hardware for flywheels, ultracapacitor-type energy storage/discharge devices for ride-through, and utility interface issues. He is the holder of four U.S. patents and has licensed two new technologies to the industry. He is the Lead Developer of the Power Quality and Distributed Energy Systems Laboratory at Texas A\&M University and is actively involved in many projects with industry, while engaged in teaching, research, and consulting in the areas of power electronics, motor drives, power quality, and clean power utility interface issues.

Dr. Enjeti was the recipient of Second Best Paper Awards in 1993, 1998, 1999 and 2001, and a Third Best Paper Award in 1996 from the IEEE Industry Applications Society (IAS). He received the Second Prize Paper Award from the IEEE TRANSACTIONS ON INDUSTRY APPLICATIONS for papers published from mid-year 1994 to mid-year 1995 and the IEEE Industry Applications Magazine Prize Article Award in the year 1996. He is a Member of the IAS Executive Board and the Chair of the Standing Committee on "Electronic Communications." He was also the recipient of the select title "Class of 2001 Texas A\&M University Faculty Fellow" for demonstrated achievement of excellence in research, scholarship, and leadership in the field. He directed a team of students to design and build a low-cost fuel cell inverter for residential applications, which won the 2001 Future Energy Challenge Award, Grand Prize, from the U.S. Department of Energy. He is a Registered Professional Engineer in the State of Texas. 